\section{O ambiente alimentar comunitário e a presença de pântanos alimentares no entorno das escolas de uma metrópole brasileira}

\author{
Community food environment and presence \\ of food swamps around schools in \\ a Brazilian metropolis
}

\section{El ambiente alimentario comunitario y la presencia de establecimientos de comida ultraprocesada en el entorno de las escuelas de una metrópoli brasileña}

\author{
Carla Marien da Costa Peres 1 \\ Bruna Vieira de Lima Costa 1 \\ Milene Cristine Pessoa 1 \\ Olivia Souza Honório 2 \\ Ariene Silva do Carmo 1 \\ Thales Philipe Rodrigues da Silva 1 \\ Danielle Soares Gardone 1 \\ Adriana Lúcia Meireles 2 \\ Larissa Loures Mendes 1
}

\section{Resumo}

O objetivo foi avaliar o ambiente alimentar comunitário e a existência de pântanos alimentares no entorno das escolas de uma metrópole brasileira. Trata-se de um estudo ecológico realizado em escolas públicas e privadas de Belo Horizonte, Minas Gerais, Brasil, e teve como unidade de análise o buffer de 250m. Foram incluidas no estudo todas as escolas de Educação Infantil, de Ensinos Fundamental e Médio. Em relação às escolas, foram avaliadas a dependência administrativa e o tipo de ensino ofertado, bem como a renda per capita dos setores censitários das escolas. Contabilizou-se também as informações sobre os estabelecimentos de venda de alimentos para o consumo imediato que estavam dentro do buffer no entorno das escolas. Em relação ao ambiente alimentar foram avaliados apenas os estabelecimentos que comercializam alimentos para o consumo imediato no entorno escolar. A análise dos buffers revelou que $97,4 \%$ das escolas tinham ao menos um desses estabelecimentos no seu entorno. Os estabelecimentos mais disponiveis no entorno da escola foram lanchonetes, restaurantes e bares. As escolas localizadas em setores censitários de maior renda apresentavam maior média de todos os estabelecimentos no seu entorno, exceto das mercearias e supermercados. Ademais, 54,6\% das escolas estavam em vizinhanças que são classificados como pântanos alimentares. Os resultados revelam que entre as categorias avaliadas ocorre um predominio dos estabelecimentos que comercializam, predominantemente, alimentos ultraprocessados, como os bares e lanchonetes no entorno das escolas de Belo Horizonte, o que expõe as crianças e os adolescentes a um ambiente alimentar não saudável.

Ambiente Construído; Alimentos Industrializados;

Saúde da População Urbana

\author{
Correspondência \\ O. S. Honório \\ Universidade Federal de Ouro Preto. \\ Rua Dois 607, Ouro Preto, MG 35400-000, Brasil. \\ oliviashonorio@gmail.com \\ 1 Universidade Federal de Minas Gerais, Belo Horizonte, Brasil. \\ 2 Universidade Federal de Ouro Preto, Ouro Preto, Brasil.
}




\section{Introdução}

O ambiente alimentar pode ser definido segundo o ambiente físico, econômico, político e sociocultural em que os indivíduos interagem e consequentemente são influenciados para a escolha, preparo e consumo dos alimentos 1. Esse ambiente alimentar pode, por sua vez, ser divido em níveis como: comunitário, organizacional, do consumidor e de informação 2. Em relação ao ambiente alimentar comunitário, este refere-se à distribuição, número, tipo, localização e acessibilidade aos estabelecimentos que comercializam alimentos 2 . O ambiente organizacional está relacionado aos estabelecimentos que comercializam alimentos que estão localizados dentro de instituições, como por exemplo, nas escolas 2. A Organização das Nações Unidas para a Alimentação e a Agricultura (FAO) propõe um conceito mais ampliado para o ambiente alimentar das escolas, considerando que este diz respeito aos espaços e infraestruturas disponíveis onde os alimentos podem ser obtidos, comprados e/ou consumidos dentro e ao redor das escolas, que também inclui o ambiente alimentar de informação (marketing, anúncios, rótulos de alimentos, promoções etc.) e pode ser um importante fator associado à obesidade em crianças e adolescentes, dependendo da disponibilidade, do acesso e dos tipos de alimentos comercializados 3 .

No contexto da alimentação e nutrição, a abordagem do ambiente alimentar escolar reconhece a importância da disponibilidade e do acesso a alimentos saudáveis dentro e fora das escolas como determinantes do consumo de crianças e adolescentes, uma vez que, para este grupo, os comportamentos são influenciados principalmente pela família e pelo ambiente escolar 4,5 . Além disso, é preciso considerar que as crianças e adolescente estão na fase de crescimento e desenvolvimento, por isto necessitam de uma alimentação saudável, capaz de ofertar todos os nutrientes necessários durante este período 6 . Nesse cenário, a literatura demonstra que o padrão alimentar adotado por crianças e adolescente está em direção oposta ao recomendado, uma vez que neste grupo prevalece o elevado consumo de alimentos não saudáveis e o baixo consumo de alimentos saudáveis 7,8,9. São considerados alimentos saudáveis aqueles in natura e minimamente processados e os não saudáveis os alimentos ultraprocessados 10, sendo que esta ideia se estende para classificar os estabelecimentos considerando-se o perfil de aquisição de alimentos 11 .

Nesse sentido, o acesso físico aos alimentos no entorno escolar tem sido considerado um pontochave para a compreensão da influência do ambiente nas escolhas alimentares de crianças e adolescentes e, quando tal ambiente contribui para escolhas alimentares não saudáveis, ele é considerado obesogênico 1,12. Estudos mostram que a menor distância e a maior densidade de estabelecimentos que comercializam alimentos não saudáveis no entorno escolar estão associadas a escolhas alimentares pouco nutritivas e densamente energéticas por crianças e adolescentes, contribuindo para o consumo alimentar inadequado e ganho de peso 13,14,15.

Considerando que existem evidências de que o ambiente no entorno das escolas tem características de um ambiente obesogênico 16,17, é importante a avaliação da existência dos pântanos alimentares, que são as vizinhanças em que as opções de alimentos não saudáveis são abundantes 18, no domínio do ambiente alimentar das escolas.

É necessário, ainda, avançar na temática do ambiente alimentar escolar em países de baixa e média rendas como o Brasil, pois diferentemente do que acontece em países desenvolvidos 15 , nestes ainda são poucas as evidências e intervenções focadas no potencial obesogênico e tóxico desse ambiente 19,20,21. Diante disso, este estudo tem por objetivo avaliar o ambiente alimentar comunitário e a existência de pântanos alimentares no entorno das escolas de uma metrópole brasileira.

\section{Métodos}

\section{Delineamento do estudo}

É um estudo ecológico, realizado com todas as escolas públicas e privadas da cidade de Belo Horizonte, capital do Estado de Minas Gerais. A cidade é a sexta mais populosa do Brasil, sendo a primeira do estado, com 2.375.151 habitantes, densidade demográfica de 7.167 habitantes $/ \mathrm{km}^{2}$ e Índice de Desenvolvimento Humano (IDH) de 0,810 (Instituto Brasileiro de Geografia e Estatística - IBGE. 
Belo Horizonte. https://cidades.ibge.gov.br/brasil/mg/belo-horizonte/panorama, acessado em 08/ Mar/2018).

Foram excluídas do estudo as instituições de Ensino Superior ou profissionalizantes, visto que seu público-alvo é composto majoritariamente por adultos. Os dados das escolas foram obtidos no site da Secretaria Estadual de Educação (SEE/MG) e são referentes ao ano de 2017. O banco final foi constituído com escolas que ofertavam Educação Infantil, Ensino Fundamental e Ensino Médio, totalizando 1.436 instituições.

\section{Dados ambientais}

Para caracterizar o ambiente alimentar comunitário no entorno das escolas de Belo Horizonte, foi desenvolvido um banco de dados com informações do endereço das escolas inseridas no estudo e dos estabelecimentos de venda de alimentos de consumo imediato, utilizando-se a Classificação Nacional de Atividades Econômicas (CNAE - https://concla.ibge.gov.br/classificacoes/por-tema/ atividades-economicas/classificacao-nacional-de-atividades-economicas.html) referente ao ano de 2015. O banco de dados dos estabelecimentos que comercializam alimentos foi construído baseandose nas informações de duas fontes governamentais: Superintendência de Arrecadação e Informações Fiscais da Secretaria da Fazenda do Estado de Minas Gerais e a da Secretaria Municipal Adjunta de Fiscalização. Os bancos de dados foram sobrepostos a fim de excluir os estabelecimentos duplicados. Os estabelecimentos discordantes entre as duas fontes de dados foram conferidos utilizando-se a ferramenta Google Street View (https://maps.google.com.br) 22. Após a conferência, foram identificados 13.504 estabelecimentos.

Os estabelecimentos de venda de alimentos analisados no entorno das escolas foram aqueles que comercializam alimentos e refeições para o consumo imediato; foi realizada uma adaptação da classificação proposta por Assis 23, foram incluídos os supermercados, hipermercados e mercearias. Esses estabelecimentos foram incluídos pois neles é possível adquirir alimentos para o consumo imediato, principalmente os ultraprocessados 11. Foram considerados como estabelecimentos para o consumo imediato: lanchonetes, lojas de doces, bares, restaurantes, padarias, supermercados, hipermercados e mercearias (Material Suplementar: http://cadernos.ensp.fiocruz.br/static//arquivo/ suppl-csp-2051-20_4058.pdf). As lojas de departamento e de conveniência não foram incluídas pois não são especializadas em comercializar alimentos, apesar de ser identificada a venda destes produtos. Ademais, de acordo com um estudo técnico realizado pela Câmara Interministerial de Segurança Alimentar e Nutricional (CAISAN), os estabelecimentos que comercializam alimentos podem ser classificados em: (1) aqueles onde a aquisição de alimentos in natura ou minimamente processados representa mais de $50 \%$ da aquisição total, ou seja, nestes estabelecimentos há uma predominância de aquisição de produtos saudáveis; (2) aqueles onde a aquisição de alimentos ultraprocessados representa mais de $50 \%$ da aquisição total, ou seja, nestes estabelecimentos há uma predominância de aquisição de produtos não saudáveis e (3) onde há predominância de aquisição de preparações culinárias ou alimentos processados ou onde não há predominância de aquisição de alimentos in natura/minimamente processados nem de alimentos ultraprocessados, estabelecimentos tidos como mistos 11.

Como unidade de análise para avaliar o ambiente alimentar, utilizou-se o buffer euclidiano de 250 metros no entorno de cada escola, que corresponde a, aproximadamente, cinco minutos de caminhada. Como centroide do buffer usou-se a localização da escola. O tamanho do buffer foi considerado com base na distância que crianças e adolescentes usualmente transitam no entorno das escolas, acompanhadas ou não por seus pais ou responsáveis 24,25. Baseando-se na criação dos buffers, foi possível contabilizar cada tipo de estabelecimento de venda de alimentos no entorno das escolas e, posteriormente, comparar o ambiente alimentar entre os tipos de ensino, dependência administrativa e tercis de renda média.

Para identificar os pântanos alimentares no entorno das escolas, foi usada uma adaptação da metodologia proposta por Hager et al. 26, que propuseram avaliar estes pântanos no entorno das residências dos adolescentes. Esses autores consideram como pântanos alimentares as vizinhanças com elevada disponibilidade de lojas de conveniência, e pequenas mercearias 26; no presente estudo as lojas de conveniência foram substituídas pelas lanchonetes. A substituição dessas lojas pelas lanchonetes ocorre no contexto em que as lanchonetes são uma das categorias de estabelecimentos mais frequen- 
tados entre os brasileiros 27, e entre os adolescentes o hábito de frequentar estes estabelecimentos está associado com padrão alimentar não saudável 28. Ademais, as lanchonetes são um dos estabelecimentos mais frequentes na base de dados analisada.

Para o cálculo, realizou-se o somatório do número de lanchonetes, mercearias e lojas de doce no entorno das escolas e, quando encontrado somatório maior ou igual a quatro estabelecimentos, o local foi classificado como pântano alimentar. Para a análise desses pântanos também utilizou-se o buffer circular de 250 metros no entorno das escolas como unidade de análise.

\section{Dados de renda}

As informações sobre a renda foram obtidas no Censo Demográfico de 2010 do IBGE (http://censo 2010.ibge.gov.br/resultados.html), referentes aos limites geográficos dos setores censitários urbanos do município. Para verificar a renda per capita do setor censitário da escola foram utilizados os dados de renda e de população do censo.

Posteriormente, a variável quantitativa contínua "renda per capita dos setores censitários" foi categorizada em tercis de renda (em Reais): 1 o tercil (159,60 -| 571,58); 2 o tercil (571,59 -| 1.193,88); e 3o tercil $(1.193,89$ - 8.388,16). Com base nesses dados, foi atribuído à escola o tercil de renda referente ao setor censitário no qual a ela estava localizada.

\section{Análise de dados}

As coordenadas geográficas (latitude e longitude) das escolas e dos estabelecimentos de venda de alimentos foram obtidas baseando-se nos endereços por meio do uso do serviço online de pesquisa Google Maps (https://www.google.com.br/maps?hl=pt-BR). Os dados foram coletados em configuração de Sistema de Coordenadas Geográficas WGS 84 e posteriormente transformados para o Sistema de Coordenadas Projetadas, Sistema Universal Transverso de Mercator (UTM), fuso 23S, datum SIRGAS 2000, por meio do uso do software Qgis 2.10.1 (https://qgis.org/pt_BR/site/).

Foram realizadas análises descritivas com medidas de frequências, medidas de tendência central (média) e dispersão (desvio padrão). Comparou-se o ambiente alimentar das escolas segundo os tipos de ensino, dependência administrativa e tercis de renda média per capita. Para tanto, foi utilizado o software estatístico Stata, versão 14.0 (https://www.stata.com).

\section{Resultados}

Das 1.436 escolas incluídas no estudo, $882(61,42 \%)$ eram da rede privada e $554(38,58 \%)$ eram da rede pública; em relação ao tipo de ensino, $616(42,9 \%)$ ofertavam educação infantil e $820(57,1 \%)$ eram de Ensino Fundamental/Médio. Dentre as escolas privadas, 409 (46,9\%) estavam localizadas em setores censitários de maior tercil de renda e dentre as públicas, 237 (44,38\%) estavam no 2o tercil de renda. Em relação ao ambiente alimentar, foram identificados 13.504 estabelecimentos que comercializam alimentos ou refeições para o consumo imediato. Os estabelecimentos mais frequentes no entorno das escolas foram as lanchonetes $(29,02 \%)$, os restaurantes $(28,06 \%)$ e os bares $(21,5 \%)$ (dados não apresentados).

Verificou-se que no buffer de 250 metros no entorno das escolas a média de estabelecimentos que comercializam alimentos ou refeições para o consumo imediato foi de 13,30 $( \pm 16,30)$. Ao avaliar segundo a categoria de estabelecimentos, observou-se que as lanchonetes $(4,10 \pm 7,50)$, restaurantes $(3,60 \pm 5,70)$ e os bares $(2,80 \pm 2,80)$ eram as categorias que apresentavam as maiores médias. Além disso, 97,4\% das escolas tinham ao menos um estabelecimento de consumo imediato no buffer de 250 metros, sendo que $82,2 \%$ dos buffers apresentaram pelo menos uma lanchonete, $82,9 \%$ pelo menos um bar e $78 \%$ pelo menos um restaurante (Tabela 1).

As lanchonetes também foram os estabelecimentos com as maiores médias, independentemente do tipo de escola (pública ou privada) e tipo de ensino (Infantil ou Fundamental/Médio). Com exceção das mercearias, a média de todos os tipos de estabelecimentos foi maior no entorno de escolas privadas e que ofertavam Ensino Fundamental/Médio. Quando avaliada a renda per capita do entorno 
das escolas, os resultados apontaram que na medida em que há aumento da renda per capita do setor censitário eleva-se também a média de todos os estabelecimentos, exceto as mercearias e os supermercados (Tabela 2).

Considerando-se a disponibilidade de estabelecimentos não saudáveis nos buffers avaliados, verificou-se que 54,6\% das escolas estavam inseridas em um buffer classificado como pântano alimentar. As escolas localizadas em pântanos alimentares estavam em sua maioria em setores censitários do 2o tercil $(39,54 \%)$ e 3 o tercil de renda per capita, eram escolas privadas (66,07\%) e ofertavam Ensino Fundamental/Médio (58,16\%) (Figura 1).

Em relação as 37 escolas (2,58\%) que não contavam com nenhum estabelecimento de consumo imediato em seu entorno, estas estavam localizadas em sua maioria $(41,18 \%$ ) no 3 o tercil ( e em menores proporções $(23,53 \%)$ no 1 o tercil de renda. No que diz respeito à dependência administrativa, a maioria das escolas sem nenhum estabelecimento no seu entorno era pública $(59,46 \%)$ e ofertava Ensino Fundamental (51,35\%) (dados não mostrados).

\section{Tabela 1}

Distribuição dos estabelecimentos de venda de alimentos no entorno escolar, buffer de 250 metros. Belo Horizonte, Minas Gerais, Brasil, 2015.

\begin{tabular}{|c|c|c|c|c|}
\hline & \multicolumn{4}{|c|}{ Escolas com pelo menos 1 estabelecimento } \\
\hline & $\boldsymbol{\mu}$ & DP & $\mathbf{n}$ & $\%$ \\
\hline Bares & 2,80 & 2,80 & 1.191 & 82,90 \\
\hline Lojas de doces e guloseimas & 0,50 & 1,30 & 353 & 24,60 \\
\hline Lanchonetes & 4,10 & 7,50 & 1.180 & 82,20 \\
\hline Mercearias & 1,20 & 1,70 & 829 & 57,70 \\
\hline Padarias & 0,90 & 1,10 & 828 & 57,60 \\
\hline Restaurantes & 3,60 & 5,70 & 1.120 & 78,00 \\
\hline Supermercados e hipermercados & 0,17 & 0,50 & 196 & 13,60 \\
\hline Total & 13,30 & 16,30 & 1.399 & 97,40 \\
\hline
\end{tabular}

$\mu$ : média; DP: desvio padrão.

\section{Tabela 2}

Distribuição dos estabelecimentos de venda de alimentos no entorno escolar, buffer de 250 metros segundo categorias, de acordo com as características das escolas. Belo Horizonte, Minas Gerais, Brasil, 2015.

\begin{tabular}{|c|c|c|c|c|c|c|c|c|c|c|c|c|c|c|c|c|}
\hline & \multicolumn{2}{|c|}{ Bares } & \multicolumn{2}{|c|}{$\begin{array}{l}\text { Lojas de } \\
\text { doces }\end{array}$} & \multicolumn{2}{|c|}{ Lanchonetes } & \multicolumn{2}{|c|}{ Mercearias } & \multicolumn{2}{|c|}{ Padarias } & \multicolumn{2}{|c|}{ Restaurantes } & \multicolumn{2}{|c|}{$\begin{array}{c}\text { Supermerca- } \\
\text { dos e hiper- } \\
\text { mercados }\end{array}$} & \multicolumn{2}{|c|}{ Total } \\
\hline & $\mu$ & DP & $\mu$ & DP & $\mu$ & DP & $\mu$ & DP & $\mu$ & DP & $\boldsymbol{\mu}$ & DP & $\boldsymbol{\mu}$ & DP & $\boldsymbol{\mu}$ & DP \\
\hline \multicolumn{17}{|l|}{ Tipo de escola } \\
\hline Pública & 2,45 & 2,19 & 0,34 & 0,95 & 3,15 & 5,30 & 1,24 & 1,45 & 0,86 & 1,01 & 2,67 & 4,33 & 0,13 & 0,41 & 10,85 & 11,27 \\
\hline Privada & 3,0 & 3,12 & 0,52 & 1,52 & 4,68 & 8,59 & 1,21 & 1,89 & 0,97 & 1,22 & 4,23 & 6,39 & 0,20 & 0,53 & 14,86 & 18,70 \\
\hline \multicolumn{17}{|l|}{ Tipo de ensino } \\
\hline Educação Infantil & 2,71 & 2,63 & 0,35 & 1,11 & 3,15 & 5,11 & 1,39 & 1,89 & 0,88 & 0,98 & 3,02 & 4,65 & 0,16 & 0,48 & 11,65 & 12,68 \\
\hline Médio/Fundamental & 2,9 & 2,94 & 0,53 & 1,48 & 4,79 & 8,86 & 1,10 & 1,60 & 0,97 & 1,26 & 4,09 & 6,39 & 0,18 & 0,50 & 14,56 & 18,55 \\
\hline \multicolumn{17}{|l|}{ Renda per capita (em Reais) } \\
\hline 1o tercil $(159,60-\mid 571,58)$ & 2,22 & 2,07 & 0,20 & 0,52 & 1,85 & 2,21 & 1,78 & 1,81 & 0,92 & 1,10 & 1,27 & 1,50 & 0,16 & 0,56 & 8,42 & 5,76 \\
\hline 2o otercil $(571,59-\mid$ 1.193,88) & 2,86 & 2,30 & 0,27 & 0,57 & 2,77 & 2,77 & 1,28 & 1,32 & 0,94 & 1,00 & 2,05 & 2,08 & 0,18 & 0,46 & 10,35 & 6,42 \\
\hline 3o tercil $(1.193,89-\mid 8.388,16)$ & 3,13 & 3,48 & 0,77 & 1,99 & 6,65 & 11,01 & 0,87 & 1,96 & 0,95 & 1,33 & 6,66 & 8,09 & 0,17 & 0,46 & 19,20 & 23,88 \\
\hline
\end{tabular}

$\mu$ : média; DP: desvio padrão. 


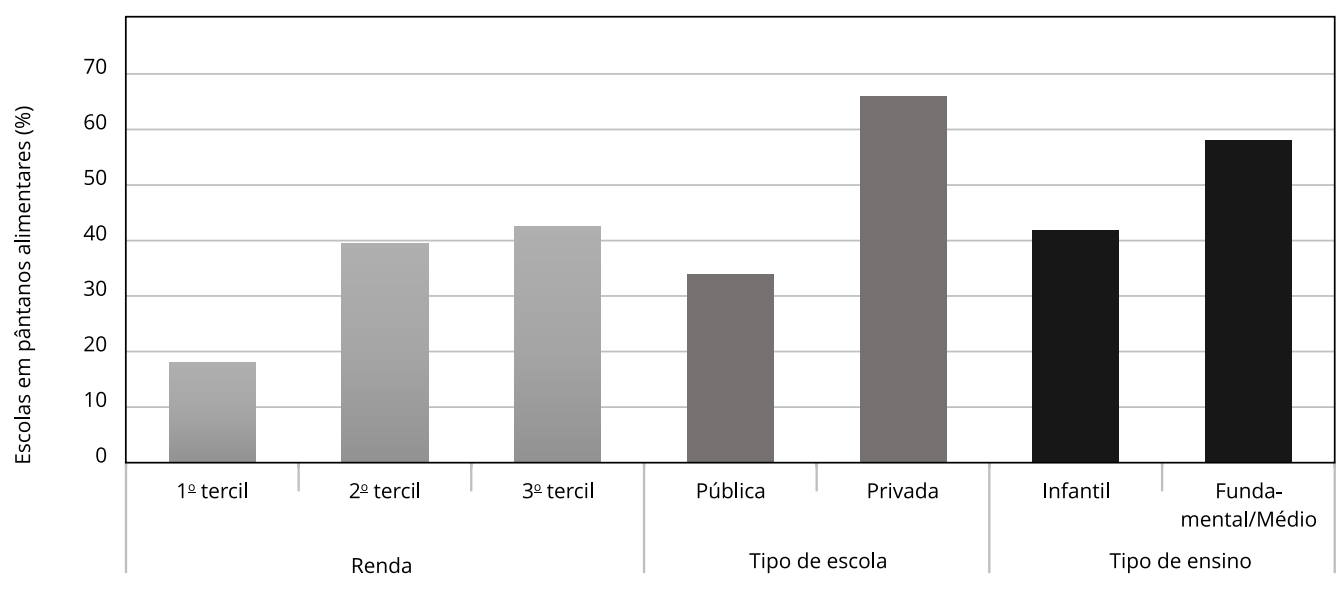

Nota: a porcentagem de pântanos alimentares no entorno da escola foi avaliada segundo a renda do setor censitário da escola, tipo de escola e tipo de ensino.

\section{Discussão}

O presente estudo é um dos primeiros a avaliar o ambiente alimentar comunitário no entorno escolar de uma metrópole brasileira, considerando estabelecimentos de venda de alimentos para o consumo imediato e os pântanos alimentares. Os resultados mostraram que dentro das categorias de estabelecimentos estudados, os mais disponíveis no entorno das escolas foram as lanchonetes, bares e restaurantes, e a maioria das escolas estava localizada em buffers classificados como pântano alimentar. Diversos estudos têm demonstrado a importância da avaliação do ambiente alimentar comunitário no entorno das escolas e a forma como estes influenciam as escolhas alimentares de crianças e adolescentes 15,29. A análise do ambiente alimentar no entorno da escola é ainda mais relevante ao se considerar que em Belo Horizonte este ambiente impacta 470.691 alunos matriculados, de acordo com o Censo Escolar de 2017, nas escolas públicas e privadas da cidade (https://cidades.ibge.gov.br/brasil/mg/ belo-horizonte/panorama).

Independentemente do tipo de escola (pública ou privada) ou do tipo de ensino ofertado, as lanchonetes, os bares e os restaurantes foram os estabelecimentos de venda de alimentos mais frequentes no entorno das escolas. No Brasil, lanchonetes e bares são os estabelecimentos que comercializam predominantemente alimentos ultraprocessados 11, e um estudo realizado com crianças e adolescentes mostrou que o hábito de comprar alimentos em lanchonetes foi associado ao aumento da ingestão de alimentos ultraprocessados 30. Na mesma direção, estudos que avaliaram o ambiente alimentar no entorno das escolas em diversos países mostraram que os alimentos comercializados eram geralmente de baixa qualidade nutricional e que as crianças e adolescentes estavam expostos a um ambiente alimentar obesogênico 16,19,31,32,33.

Quanto à avaliação do ambiente alimentar comunitário segundo a renda, os resultados mostraram uma maior predominância de estabelecimentos considerados não saudáveis (bares, lojas que comercializam doces e guloseimas e lanchonetes) no tercil de maior renda dos setores censitários das escolas. Sabe-se que as características socioeconômicas da vizinhança podem influenciar o ambiente alimentar, visto que as instalações dos estabelecimentos comerciais tendem a ser mais frequentes em locais de maior renda 34,35. Dessa forma, vizinhanças de menor renda costumam apresentar menor disponibilidade e variedade de estabelecimentos de venda de alimentos, com acesso mais limitado aos alimentos saudáveis e maior exposição à venda dos alimentos não saudáveis 36,37,38. 
Diante da elevada presença de estabelecimentos que comercializam alimentos ultraprocessados no entorno das escolas, também foi encontrado que a maioria das escolas estava localizada em pântanos alimentares. Esses pântanos vêm sendo associados ao aumento de taxas de obesidade 39, de internações por complicações de algumas doenças crônicas 40 e alimentação não saudável 41 . Em Baltimore (Estados Unidos), um estudo realizado com adolescentes que cursavam as 6a e e 7a séries avaliou a associação do ambiente alimentar com o consumo de lanches e concluiu que residir em áreas de pântanos alimentares associou-se ao maior consumo destes 26 .

Outros trabalhos também encontraram maior concentração de lojas de conveniência e restaurantes fast food, estabelecimentos utilizados como marcadores de alimentação não saudável, no entorno das escolas secundárias (Ensino Médio), o que pode ser justificado pelo fato de os adolescentes apresentarem maior autonomia para comprar alimentos, bem como maior mobilidade para percorrerem maiores distâncias no entorno escolar ou entre o domicílio e a escola 42,43,44, e apesar de não ter sido avaliada a presença dos pântanos alimentares, verificou-se um ambiente alimentar obesogênico e tóxico 16,17 .

Outro achado relevante do presente trabalho, complementar à questão dos pântanos alimentares, foi a presença de bares no entorno escolar. Esses estabelecimentos são caracterizados por venderem, principalmente, alimentos e bebidas ultraprocessados 11, sendo, portanto, um local adicional para a aquisição de alimentos ultraprocessados. Além disso, tem o aspecto relacionado ao aumento da disponibilidade de bebidas alcoólicas no entorno das escolas. Uma vez que é amplamente discutido na literatura que à proporção que o álcool se torna mais acessível, o consumo e os problemas relacionados a ele aumentam, sendo este um achado relevante que deve ser considerado pelos gestores ao propor políticas que incluam a população escolar 45,46 .

Ademais, um estudo que encontrou características do ambiente alimentar similares às observadas no presente trabalho, relata que existe associação destas características com o comportamento alimentar de crianças e adolescentes, fazendo com que este grupo escolha uma alimentação monótona e densamente energética, o que favorece o desenvolvimento de obesidade 16. No Brasil, já existem dados que apontaram que $26,7 \%$ das calorias consumidas pelas crianças e adolescentes (10 a 18 anos) são provenientes de alimentos ultraprocessados. E ao comparar com a ingestão de adultos e idosos, as crianças e adolescentes são o grupo com a maior ingestão de alimentos ultraprocessados e a menor ingestão de alimentos in natura. Além disso, alimentos como salgados fritos e assados, sorvete/picolé, bolos recheados, salgadinhos chips e refrigerantes estão entre aqueles com o maior percentual de consumo fora do domicilio em áreas urbanas no Brasil 47.

É importante destacar que o ambiente organizacional também influencia nas escolhas alimentares de crianças e adolescentes, sendo que em escolas privadas é comum a presença de cantinas. Um estudo que avaliou escolas públicas e privadas no Brasil encontrou que a presença de cantinas era maior nas escolas privadas $(97,75 \%)$ e que estas também apresentavam mais propaganda e comércio de alimentos processados e ultraprocessados 48. Além disso, vale destacar que as escolas públicas no Brasil são assistidas pelo Programa Nacional de Alimentação Escolar (PNAE), que tem por objetivo promover hábitos alimentares saudáveis por meio da oferta de alimentação saudável e de ações de educação alimentar e nutricional 49.

Os achados deste trabalho possibilitaram compreender como é a distribuição dos estabelecimentos para o consumo imediato no entorno de escolas públicas e privadas, avançando principalmente no sentido de investigar a existência de pântanos alimentares no entorno deste ambiente organizacional. Porém, entendemos que precisam ser realizadas pesquisas futuras com o intuito de entender o ambiente de informação dentro e no entorno dessas escolas e também avaliar a presença do comércio informal de alimentos. Temos como limitação o uso de fontes de dados secundárias para a localização das escolas e dos estabelecimentos de venda de alimentos, o que pode gerar imprecisões. Porém, a junção de duas bases de dados no caso dos estabelecimentos e a conferência virtual permitiram uma base de dados mais confiável para a avaliação do ambiente alimentar no entorno das escolas.

Outra potencial limitação diz respeito ao uso do buffer euclidiano para a definição do entorno escolar, uma vez que este tipo de unidade determina limites arbitrários, ou seja, que não leva em consideração as rotas que realmente são utilizadas para o acesso às escolas. Apesar da limitação, esta tem sido uma estratégia muito usada nos estudos que avaliam o ambiente alimentar no entorno escolar. Além disso, vale ressaltar que medidas de distância baseadas em buffer euclidiano e buffer network 
$(r=0,865)$ e densidade ( $r=0,667-0,764$, dependendo do tamanho da vizinhança) têm forte correlação entre si 50 . Outra limitação em relação ao buffer diz respeito ao fato de que não foi avaliada a sobreposição dos buffers, para verificar a influência de ter escolas próximas. Além disso, existe uma diferença de tempo entre os dados secundários, o que poderia acarretar um viés de mensuração.

Ademais, algumas avaliações que não foram possíveis neste trabalho devem ser consideradas para futuros estudos como: avaliação da rota do estudante; informações sobre a aquisição de alimentos nos estabelecimentos que fazem parte do ambiente alimentar no entorno das escolas; avaliação do ambiente alimentar do consumidor (exemplo: o que está sendo vendido nas lanchonetes de Belo Horizonte? Quais os preços dos alimentos que estão sendo comercializados?) e avaliação objetiva na porta da escola relacionada aos vendedores ambulantes de alimentos.

\section{Conclusões}

As evidências encontradas neste estudo mostraram que entre as categorias avaliadas ocorre um predomínio dos estabelecimentos que comercializam, predominantemente, alimentos ultraprocessados, como os bares e as lanchonetes no entorno das escolas. Além disso, a maioria das escolas está em buffers classificados como pântanos alimentares, o que pode expor crianças e adolescentes a um ambiente alimentar obesogênico à curta distância de um local onde passam boa parte do seu tempo. Dessa forma, isso pode favorecer escolhas alimentares não saudáveis, exposição precoce a bebidas alcoólicas e, também, contribuir para o excesso de peso e comportamentos não saudáveis nesse público.

\section{Colaboradores}

C. M. C. Peres, B. V. L. Costa e L. L. Mendes contribuíram na elaboração, planejamento, redação, interpretação dos dados, revisão crítica do conteúdo e aprovação da versão final. M. C. Pessoa e A. L. Meireles contribuíram na revisão crítica do manuscrito. O. S. Honório, Ariene Silva do Carmo, T. P. R. Silva e D. S. Garbone contribuíram na análise dos dados e revisão crítica do manuscrito.

\section{Informações adicionais}

ORCID: Carla Marien da Costa Peres (00000002-2254-3351); Bruna Vieira de Lima Costa (0000-0003-3552-7729); Milene Cristine Pessoa (0000-0002-1053-5450); Olivia Souza Honório (0000-0003-4174-6987); Ariene Silva do Carmo (0000-0002-3421-9495); Thales Philipe Rodrigues da Silva (0000-0002-7115-0925); Danielle Soares Gardone (0000-0003-4632-3924); Adriana Lúcia Meireles (0000-0002-1447-953X); Larissa Loures Mendes (0000-0003-0776-6845).

\section{Referências}

1. Swinburn B, Sacks G, Vandevijvere S, Kumanyika S, Lobstein T, Neal B, et al. INFORMAS (International Network for Food and Obesity/ non-communicable diseases Research, Monitoring and Action Support): overview and key principles. Obes Rev 2013; 14 Suppl 1:1-12.

2. Glanz K, Sallis JF, Saelens BE, Frank LD. Healthy nutrition environments: concepts and measures. Am J Health Promot 2005; 19:330-3.

3. Food and Agriculture Organization of the United Nations. School food and nutrition framework. Rome: Food and Agriculture Organization of the United Nations; 2019.

4. Swinburn B, Vandevijvere S. WHO report on ending childhood obesity echoes earlier recommendations. Public Health Nutr 2016; 19:1-2.

5. Haddad J, Ullah S, Bell L, Leslie E, Magarey A. The influence of home and school Environments on children's diet and physical activity, and body mass index: a structural equation modelling approach. Matern Child Health J 2018; 22:364-75. 
6. Vitolo MR. Nutrição da gestação ao envelhecimento. Rio de Janeiro: Editora Rubio; 2008.

7. Costa SMM, Horta PM, Santos LC. Food advertising and television exposure: influence on eating behavior and nutritional status of children and adolescents. Arch Latinoam Nutr 2012; 62:53-9.

8. Instituto Brasileiro de Geografia e Estatística. Pesquisa Nacional de Saúde do Escolar 2015. Rio de Janeiro: Instituto Brasileiro de Geografia e Estatística; 2016.

9. Carmo AS, Sousa TM, Silva CM, Silva AR, Silva AC, Lacerda AT, et al. Nutritional intervention based on ludic activities: effect on eating habits and nutritional status of Brazilian schoolchildren. J Food Nutr Res (Newark) 2018; 6:302-5.

10. Departamento de Atenção Básica, Secretaria de Atenção à Saúde, Ministério da Saúde. Guia alimentar para a população brasileira. 2a Ed. Brasília: Ministério da Saúde; 2014.

11. Câmara Interministerial de Segurança Alimentar e Nutricional. Mapeamento dos desertos alimentares no Brasil. Brasília: Ministério do Desenvolvimento Social; 2018.

12. Swinburn B, Egger G, Raza F. Dissecting obesogenic environments: the development and application of a framework for identifying and prioritizing environmental interventions for obesity. Prev Med 1999; 29(6 Pt 1):563-70.

13. Boone-Heinonen J, Gordon-Larsen P. Obesogenic environments in youth: concepts and methods from a longitudinal national sample. Am J Prev Med 2012; 42:e37-46.

14. Barquera S, Hernández-Barrera L, Rothenberg SJ, Cifuentes E. The obesogenic environment around elementary schools: food and beverage marketing to children in two Mexican cities. BMC Public Health 2018; 18:461.

15. Peres CMC, Gardone DS, Mendes LL, Costa BVL, Duarte CK, Pessoa MC. Retail food environment around schools and overweight: a systematic review. Nutr Rev 2020; 78:841-56.

16. Day PL, Pearce J. Obesity-promoting food environments and the spatial clustering of food outlets around schools. Am J Prev Med 2011; 40:113-21.

17. Barrera LH, Rothenberg SJ, Barquera S, Cifuentes E. The toxic food environment around elementary schools and childhood obesity in Mexican cities. Am J Prev Med 2016; 51:264-70.

18. Zhang T, Huang B. Local Retail food environment and consumption of fruit and vegetable among adults in Hong Kong. Int J Environ Res Public Health 2018; 15:2247.

19. Leite FHM, Oliveira MA, Cremm EC, Abreu DSC, Maron LR, Martins PA. Availability of processed foods in the perimeter of public schools in urban areas. J Pediatr (Rio J.) 2012; 88:328-34.

20. Leite MA. Ambiente alimentar no entorno das escolas das regiões urbanas de Juiz de Fora, Minas Gerais [Dissertação de Mestrado]. Juiz de Fora: Faculdade de Medicina, Universidade Federal de Juiz de Fora; 2017.
21. Novaes TG. Ambiente Alimentar no território das escolas urbanas de Viçosa, Minas Gerais [Dissertação de Mestrado]. Viçosa: Universidade Federal de Viçosa; 2018.

22. Leme BA, Rocha LL. Elaboração de banco de dados de estabelecimentos de venda de alimentos de uma cidade brasileira de grande porte [Monografia de Conclusão de Curso]. Belo Horizonte: Escola de Enfermagem, Universidade Federal de Minas Gerais; 2018.

23. Assis MM. Ambiente alimentar residencial e obesidade em crianças e adolescentes de uma cidade de médio porte brasileira [Dissertação de Mestrado]. Juiz de Fora: Faculdade de Medicina, Universidade Federal de Juiz de Fora; 2017.

24. Chiang P-H, Huang L-Y, Lee M-S, Tsou H-C, Wahlqvist ML. Fitness and food environments around junior high schools in Taiwan and their association with body composition: gender differences for recreational, reading, food and beverage exposures. PLoS One 2017; 12:e0182517.

25. Ortega Hinojosa AM, MacLeod KE, Balmes J, Jerrett M. Influence of school environments on childhood obesity in California. Environ Res 2018; 166:100-7.

26. Hager ER, Cockerham A, O’Reilly N, Harrington D, Harding J, Hurley KM, et al. Food swamps and food deserts in Baltimore City, MD, USA: associations with dietary behaviours among urban adolescent girls. Public Health Nutr 2017; 20:2598-607.

27. Bezerra IN, Moreira TMV, Cavalcante JB, Souza AM, Sichieri R, Bezerra IN, et al. Food consumed outside the home in Brazil according to places of purchase. Rev Saúde Pública 2017; 51:15.

28. Maia EG, Silva LES, Santos MAS, Barufaldi LA, Silva SU, Claro RM. Padrões alimentares, características sociodemográficas e comportamentais entre adolescentes brasileiros. Rev Bras Epidemiol 2018; 21:e180009.

29. Seliske LM, Pickett W, Boyce WF, Janssen I. Association between the food retail environment surrounding schools and overweight in Canadian youth. Public Health Nutr 2009; 12:1384-91.

30. Corrêa EN, Retondario A, Alves MA, Bricarello LP, Rockenbach G, Hinnig PF, et al. Utilization of food outlets and intake of minimally processed and ultra-processed foods among 7 to 14-year-old schoolchildren. A cross-sectional study. São Paulo Med J 2018; 136:200-7.

31. Austin SB, Melly SJ, Sanchez BN, Patel A, Buka S, Gortmaker SL. Clustering of fast-food restaurants around schools: a novel application of spatial statistics to the study of food environments. Am J Public Health 2005; 95:1575-81.

32. Kipke MD, Iverson E, Moore D, Booker C, Ruelas V, Peters AL, et al. Food and park environments: neighborhood-level risks for childhood obesity in east Los Angeles. J Adolesc Health 2007; 40:325-33. 
33. Engler-Stringer R, Shah T, Bell S, Muhajarine N. Geographic access to healthy and unhealthy food sources for children in neighbourhoods and from elementary schools in a mid-sized Canadian city. Spat Spatiotemporal Epidemiol 2014; 11:23-32.

34. Macintyre S, McKay L, Cummins S, Burns C. Out-of-home food outlets and area deprivation: case study in Glasgow, UK. Int J Behav Nutr Phys Act 2005; 2:16.

35. Pessoa MC, Mendes LL, Caiaffa WT, Malta DC, Velásquez-Meléndez G. Availability of food stores and consumption of fruit, legumes and vegetables in a Brazilian urban area. Nutr Hosp 2014; 31:1438-43.

36. Cummins S, Macintyre S. Food environments and obesity - neighbourhood or nation? Int J Epidemiol 2006; 35:100-4.

37. Jaime PC, Duran AC, Sarti FM, Lock K. Investigating environmental determinants of diet, physical activity, and overweight among adults in São Paulo, Brazil. J Urban Health 2011; 88:567-81.

38. Duran AC, Diez Roux AV, Latorre MRDO, Jaime PC. Neighborhood socioeconomic characteristics and differences in the availability of healthy food stores and restaurants in São Paulo, Brazil. Health Place 2013; 23:39-47.

39. Cooksey-Stowers K, Schwartz MB, Brownell KD. Food swamps predict obesity rates better than food deserts in the United States. Int J Environ Res Public Health 2017; 14:1366.

40. Phillips AZ, Rodriguez HP. Adults with diabetes residing in "food swamps" have higher hospitalization rates. Health Serv Res 2019; 54 Suppl 1:217-25.

41. Goodman M, Thomson J, Landry A. Food environment in the lower Mississippi Delta: food deserts, food swamps and hot spots. Int J Environ Res Public Health 2020; 17:3354.

42. Sturm R. Disparities in the food environment surrounding US middle and high schools. Public Health 2008; 122:681-90.
43. Zenk SN, Powell LM. US secondary schools and food outlets. Health Place 2008; 14:33646.

44. Robitaille B, Bergeron P, Lasnier B. Geographical analysis of the accessibility of fast-food restaurants and convenience stores around public schools in Québec. Québec: Institut National de Santé Publique du Québec; 2010.

45. Azar D, White V, Coomber K, Faulkner A, Livingston M, Chikritzhs T, et al. The association between alcohol outlet density and alcohol use among urban and regional Australian adolescents. Addiction 2016; 111:65-72.

46. World Health Organization. Global status report on alcohol and health 2018. Geneva: World Health Organization; 2018.

47. Instituto de Brasileiro de Geografia e Estatística. Pesquisa de Orçamentos Familiares 20172018: análise do consumo alimentar pessoal no Brasil. Rio de Janeiro: Instituto Brasileiro de Geografia e Estatística; 2020.

48. Carmo AS, Assis MM, Cunha CF, Oliveira TRPR, Mendes LL, Carmo AS, et al. The food environment of Brazilian public and private schools. Cad Saúde Pública 2018; 34:e00014918.

49. Ministério da Educação/Fundo Nacional de Desenvolvimento da Educação. Resolução CD/FNDE no 26, de 17 de junho de 2013. Dispõe sobre o atendimento da alimentação escolar aos alunos da educação básica no âmbito do Programa Nacional de Alimentação Escolar - PNAE. Diário Oficial da União 2013; 18 jun.

50. Burgoine T, Alvanides S, Lake AA. Creating 'obesogenic realities'; do our methodological choices make a difference when measuring the food environment? Int J Health Geogr 2013; $12: 33$. 
Abstract

The study aimed to assess the community food environment and the existence of food swamps around schools in a Brazilian metropolis. This was an ecological study in public and private schools in Belo Horizonte, Minas Gerais State, Brazil, with a 250-meter buffer as the analytical unit. The study included all preschool, elementary, and middle schools. In relation to the schools, the study evaluated administrative regimen (public versus private), type of teaching, and per capita income in the schools' census tracts. Information was also compiled on the retail food establishments inside the buffer zone around the schools. The food environment was characterized only according to the establishments around the schools that sold food for immediate consumption. Analysis of the buffers revealed that $97.4 \%$ of the schools had at least one establishment in the vicinity that sold food for immediate consumption. The most available establishments around schools were snack bars, restaurants, and bars. Schools located in higher-income census tracts showed higher mean numbers of all establishments in their vicinity, except for grocery stores and supermarkets. In addition, 54.6\% of the schools were in neighborhoods classified as food swamps. The results that the among the target categories, there was a predominance of establishments that mainly sell ultra-processed foods such as bars and snack bars in the vicinity of schools in Belo Horizonte, which exposes children and adolescents to an unhealthy food environment.

Built Environment; Industrialized Foods; Urban Health

\section{Resumen}

El objetivo fue evaluar el ambiente alimentario comunitario y la existencia de establecimientos de comida ultraprocesada en el entorno de las escuelas de una metrópoli brasileña. Se trata de un estudio ecológico, realizado en escuelas públicas y privadas de Belo Horizonte, Minas Gerais, Brasil, y tuvo como unidad de análisis una zona de influencia de $250 \mathrm{~m}$. Se incluyeron en el estudio todas las escuelas de educación infantil, enseñanza fundamental y media. En relación con las escuelas, se evaluó la dependencia administrativa y el tipo de enseñanza ofertada, así como la renta per cápita de los sectores censitarios de las escuelas. Se contabilizó también información sobre establecimientos de venta de alimentos para consumo inmediato que estaban dentro de la zona de influencia en el entorno de las escuelas. En relación con el ambiente alimentario, se evaluaron solamente los establecimientos que comercializan alimentos para consumo inmediato en el entorno escolar. El análisis de las zonas de influencia reveló que un 97,4\% de las escuelas poseían al menos un establecimiento en su entorno que comercializa alimentos para el consumo inmediato. Los establecimientos más disponibles en el entorno de la escuela fueron cafeterías, restaurantes y bares. Las escuelas localizadas en sectores censitarios de mayor renta presentaban mayor media de todos los establecimientos en su entorno, excepto tiendas de alimentación y supermercados. Además, un 54,6\% de las escuelas estaban en vecindarios que se clasifican como zonas con abundancia de locales con comida ultraprocesada. Los resultados revelan que entre las categorías evaluadas se produce un predominio de establecimientos que comercializan, predominantemente, alimentos ultraprocesados, como bares y cafeterías, en el entorno de las escuelas de Belo Horizonte, lo que expone a niños y adolescentes a un ambiente alimentario no saludable.

Ambiente Construido; Alimentos Industrializados; Salud Urbana
Recebido em 13/Jul/2020

Versão final reapresentada em 03/Out/2020

Aprovado em 19/Out/2020 